\title{
Ce-Sb (Cerium-Antimony)
}

\section{H. Okamoto}

The Ce-Sb phase diagram in [Massalski2] was schematically drawn based on a presumed similarity to the $\mathrm{Nd}-\mathrm{Sb}$ system. Figure 1 shows the $\mathrm{Ce}-\mathrm{Sb}$ phase diagram determined by [1997Abu] using differential thermal analysis, x-ray powder diffraction, and metallography data. Ce-Sb crystal structure data are given in Table 1.
References

1997Abu: V.D. Abulkhaev: Z. Neorg. Khim., 1997, vol. 42 (2), pp. 341-45 (in Russian); translation: Russ. J. Inorg. Chem., 1997, vol. 42 (2), pp. 283-86.

Table 1 Ce-Sb crystal structure data

\begin{tabular}{|c|c|c|c|c|c|}
\hline Phase & $\begin{array}{c}\text { Composition, } \\
\text { at. } \% \mathrm{Sb}\end{array}$ & Pearson symbol & Space group & $\begin{array}{c}\text { Strukturbericht } \\
\text { designation }\end{array}$ & Prototype \\
\hline$(\delta \mathrm{Ce})$ & 0 & $c I 2$ & $\operatorname{Im} \overline{3} m$ & $A 2$ & W \\
\hline$(\gamma \mathrm{Ce})$ & 0 & $c F 4$ & $F m \overline{3} m$ & $A 1$ & $\mathrm{Cu}$ \\
\hline$(\beta \mathrm{Ce})$ & 0 & $h P 4$ & $P 6_{3} / m m c$ & $A 3^{\prime}$ & $\alpha \mathrm{La}$ \\
\hline $\mathrm{Ce}_{2} \mathrm{Sb}$ & 33.3 & $t I 12$ & $I \underline{-} / \mathrm{mmm}$ & $\ldots$ & $\cdots$ \\
\hline $\mathrm{Ce}_{4} \mathrm{Sb}_{3}$ & 42.9 & $c 128$ & $\overline{4} 3 \underline{d}$ & $D 7_{3}$ & $\mathrm{Th}_{3} \mathrm{P}_{4}$ \\
\hline $\mathrm{CeSb}$ & 50 & $c F 8$ & $F m \overline{3} m$ & $B 1$ & $\mathrm{NaCl}$ \\
\hline$\beta \mathrm{CeSb}_{2}$ & 66.7 & $\cdots$ & $\ldots$ & $\cdots$ & $\ldots$ \\
\hline$\alpha \mathrm{CeSb}_{2}$ & 66.7 & $o C 24$ & Cmca & $\cdots$ & $\mathrm{Sb}_{2} \mathrm{Sm}$ \\
\hline$(\mathrm{Sb})$ & 100 & $h R 2$ & $R \overline{3} m$ & A7 & $\alpha$ As \\
\hline
\end{tabular}

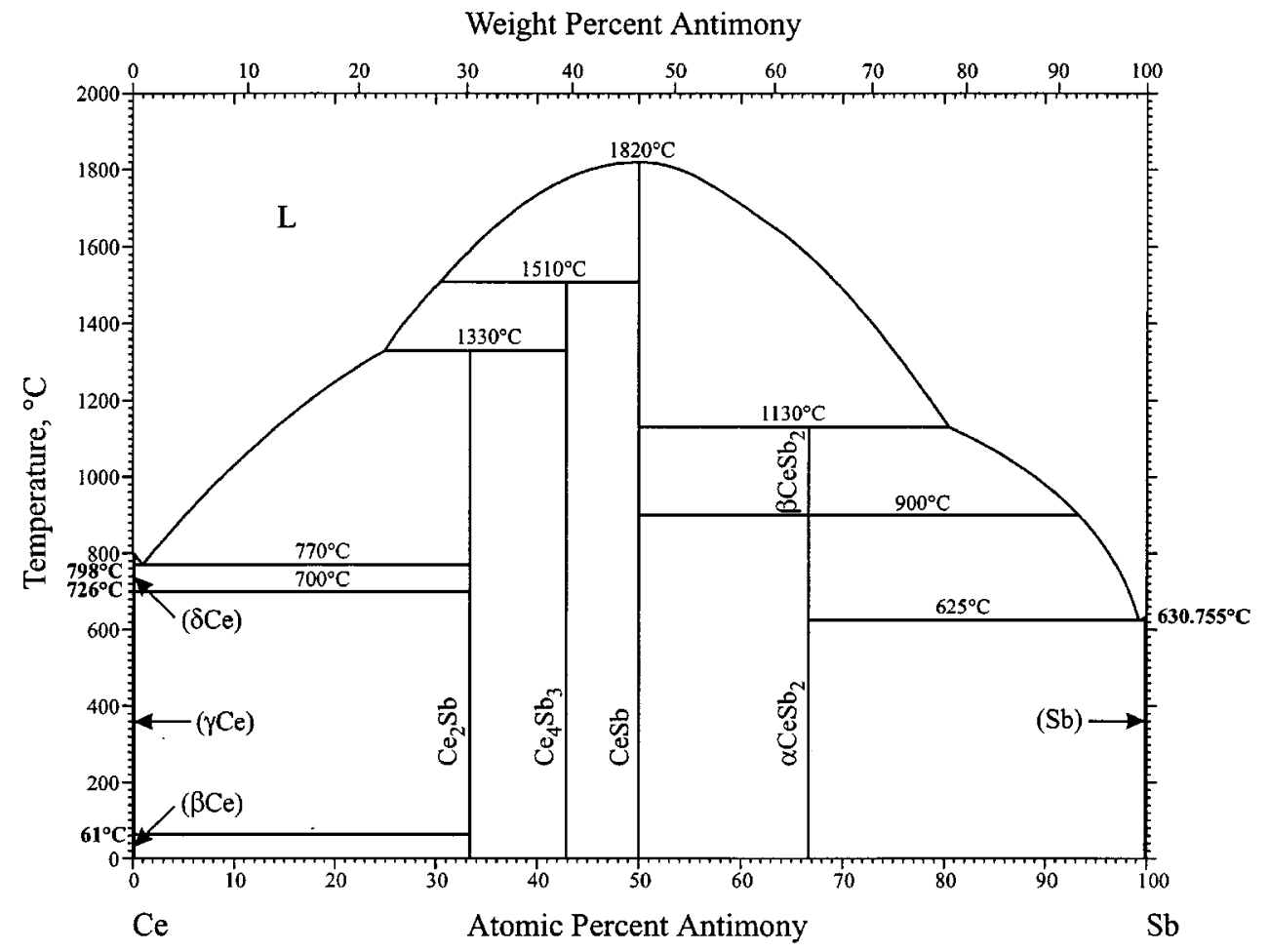

Fig. $1 \mathrm{Ce}-\mathrm{Sb}$ phase diagram 